\title{
O CONTATO ENTRE O PORTUGUÊs E AS LÍNGUAS BANTU EM MOÇAMBIQUE: A ALTERNÂNCIA DE ATITUDES SOBRE O ESTATUTO SOCIAL DAS LÍNGUAS EM JOVENS UNIVERSITÁRIOS
}

Letícia Cao Ponso

\section{RESUMO}

Este artigo pretende discutir os estatutos atribuídos às línguas autóctones moçambicanas do tronco bantu e ao português, língua ex-colonial de contato, por jovens estudantes dos primeiros semestres do curso de Letras da Universidade Eduardo Mondlane na cidade de Maputo.

PALAVRAS-CHAVE: Atitudes linguísticas; línguas moçambicanas; etnografia da fala.

"As pessoas brancas vêm aqui para nos dizer como devemos ser, e como devemos falar, e não para pesquisar quem somos e como falamos" (estudante de Letras, em Maputo)

\section{Introdução}

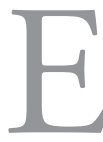

ste artigo pretende discutir, com base na pesquisa etnográfica que desenvolvi durante meu trabalho de tese doutoral, os estatutos atribuídos

- na relação de contato - às línguas autóctones moçambicanas do tronco bantu e ao português, língua ex-colonial, por jovens estudantes dos primeiros semestres do curso de Letras da Universidade Eduardo Mondlane na cidade de Maputo ${ }^{1}$. Especificamente, recorto parte da narrativa da trajetória de vida

1 Conferir sobre este mesmo tema os trabalhos de FIRMINO, 2002; MARIANI, 2004 e 2005; PATEL, 2006a e 2012; NGUNGA, 2008, CHIMBUTANE, 2009. 
de uma dessas estudantes, Manuela ${ }^{2}$, a fim de exemplificar e problematizar a complexidade do comportamento plurilíngue, não apenas em termos de quantidade de línguas e de combinações possíveis, como em termos da variabilidade de estatuto das línguas do ponto de vista do falante. Essa alternância de estatuto apresenta-se altamente variável, uma vez que quanto mais línguas houver no repertório linguístico dos sustentadores da situação de fala, línguas com suas características sóciossimbólicas particulares, mais complexas serão a relação entre as práticas e as atitudes em direção a elas. Assim, nesta comunidade de prática específica, o valor das línguas se alterna conforme os grupos de referência no sistema socioecológico que dá base à comunidade, pois as relaçôes sociais abrangem tanto laços locais como supralocais, envolvendo padróes de comportamento diferentes e às vezes conflitantes. Nessa ordem de questóes, a experiência individual do falante multilíngue ocupa um lugar especial na fissura da onipotência estrutural que sempre predominou na explicação dos fenômenos linguísticos. O que defendo aqui, com base na minha pesquisa de campo, é que não se podem medir atitudes sem pressupor que atitude é algo que se modifica, se atualiza e se negocia a cada ato de fala, com base na prática.

Tal narrativa faz parte da escrita etnográfica decorrente de uma pesquisa qualitativa empreendida ao longo de seis meses (abril a outubro de 2012). O objetivo aqui é relacionar os estatutos das línguas às experiências particulares e concretas dos sujeitos da pesquisa tentando compreendê-los à luz dos significados sóciossimbólicos de "ser plurilíngue" nesta cultura específica (GEERTZ, 1997, 2001; BRIGGS, 1986). A base teórica advém da Etnografia da Fala e da Sociolinguística Interacional, com abordagem metodológica quali-quantitativa, de cunho etnográfico e sócio-histórico. Parto dos pressupostos da Sociolinguística Interacional de base interpretativa (GUMPERZ, 1964, 1982a, 1982b), mas que busca no método etnográfico uma aproximação com a antropologia cultural e a antropologia linguística.

\section{Multilinguismo e conflito linguístico em Moçambique}

No espaço transnacional da língua portuguesa como língua pluricêntrica, chamado comumente de espaço da "lusofonia", as variedades africanas do por-

2 Para garantir-lhes o anonimato, achei por bem trocar os seus nomes e atribuir-lhes pseudônimos, seguindo a orientaçáo de Fettermann (1989, p. 133), como um meio simples de preservar sua identidade e protegê-los de algum prejuízo. 
tuguês - que, para Nataniel Ngomane (2012), não teriam uma fonia lusa, mas sim uma fonia bantu - fazem parte de um mosaico identitário, étnico e cultural marcado por identidades linguísticas híbridas. O português moçambicano, nas suas especificidades de língua ex-colonial e língua de contato ${ }^{3}$, é um campo em que se atualiza o encontro colonial, por meio do convívio entre a língua exógena europeia de colonização e as mais de vinte línguas autóctones de substrato que até hoje são a língua materna de $90 \%$ da população moçambicana ${ }^{4}$.

De acordo com Perpétua Gonçalves (2010, p. 4), os dados estatísticos dos censos da população $(1980,1997$ e 2007) apontam para estágios de evolução de número de falantes do português como primeira língua (1980 - 1.2\%; 1997 $6.5 \% ; 2007-10,7 \%)$, ao passo que, relativamente às línguas moçambicanas, há um visível recuo (1980 - 98.8\%; 1997 - 93.5\% e 2007 - 85.2\%). Para essa linguista, o português moçambicano nasce com a independência do país em 1975 , a partir dos primeiros contatos reais entre ele e as línguas moçambicanas por volta dos anos 1980. Portanto, o seu processo de nativização é muito recente.

Gráfico 1: Número de falantes de português e LB

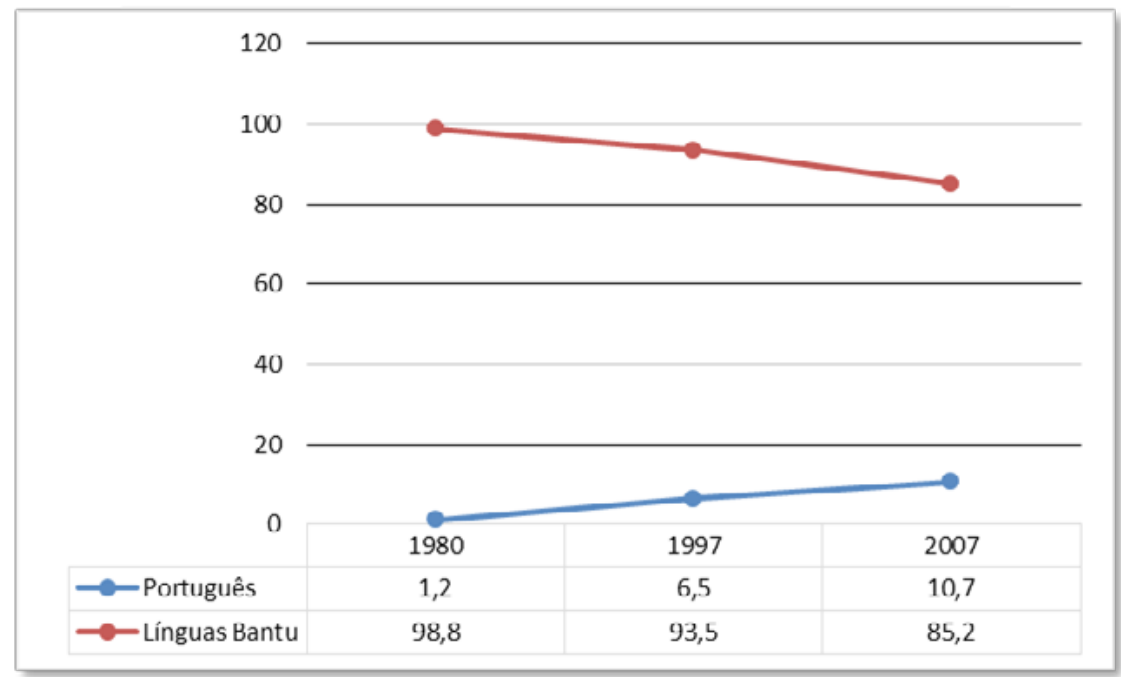

3 Cf. estudos dos linguistas moçambicanos Matabele, 1991; Lopes, 1997 e 1999; Mendes, 2006 e 2010; Dias, 2009; Gonçalves, 1996 e 2010; Firmino, 1998, 2002 e 2008; Ngunga, 2012.

4 Egundo INE, 2007. 
Firmino (2002, p. 137) afirma que em Maputo a mudança, em termos de língua materna, ocorreu entre duas gerações. Os membros de uma geração mais velha, nascida nos anos 1950/1960 mudaram das línguas autóctones para o português (dados do CENSO DE 1980), e este se tornou o idioma das atividades do dia a dia de seus descendentes, que têm uma competência mínima nas línguas autóctones para levar a cabo uma longa conversa em língua autóctone.

Os graus de proficiência das línguas usadas em Maputo variam muito, e elas se alternam conforme os domínios de uso. Firmino (2002, p. 132) afirma que "o português é, por excelência, o meio primário de comunicação da zona central de Maputo, onde constitui a escolha não-marcada em, praticamente, qualquer interação social ou informal".

Simbolicamente, o português é visto como sendo a língua da cidade e uma pessoa não se sente parte legítima da zona central, com a capacidade de ser integrada nos seus esquemas, se não tiver o seu domínio adequado. Por esta razão, aprender línguas autóctones não é um projeto tentador para a geração jovem, dada a dinâmica social da vida na zona central. (FIRMINO, 2002, p. 132)

Minha primeira impressão, provavelmente pelo contraste entre o uso categórico do português nas ruas de qualquer cidade do Brasil, contrariou de certo modo essa afirmação. Com o passar dos meses em que vivi em Maputo, comecei a separar os domínios de uso das línguas e percebi que as línguas bantu circulam mais entre os guardas, empregados, vendedores de rua, taxistas, motoristas dos chapas, comerciantes dos mercados, habitantes das zonas intermédia e periférica da cidade que vão trabalhar na zona central. Eles não são, entretanto, uma minoria, e usam preferentemente xirhonga ou xichanga$\mathrm{na}^{5}$. Ou seja: ouvi muito mais conversas em línguas moçambicanas nas ruas de Maputo do que pressupunha que ouviria. De qualquer maneira, parece-me que a predominância do português, como referida por Firmino, se dá mais em

5 Não apenas as pessoas no chapa, ou nos mercados, ou na periferia falam xirhonga ou xichangana. Certo dia, enquanto eu esperava na antessala da direçáo da Escola de Comunicação e Artes da UEM, as duas secretárias, ao falarem ao telefone, fizeram três ligaçóes falando em xirhonga. Também, ao fazer pesquisa na Rádio Moçambique, ouvi diversas vezes os funcionários a falar em xirhonga ou xichangana. 
nível sociossimbólico e nos âmbitos "privilegiados" de atuação das línguas (o português predomina no domínio oficial ou institucional como repartiçôes públicas, empresas, prestação de serviços, ONGs, restaurantes, escolas, universidade, etc.) do que propriamente na diversidade linguística das práticas cotidianas em termos demográficos.

A seleção de informantes desta pesquisa seguiu um critério pragmático: a inserção em campo através de minha própria rede de colegas na universidade, e não através de um grupo de pessoas selecionado aleatoriamente. Para mim, era importante observá-los em sua atividade de comunicação; assim, durante seis meses, assisti às aulas da cadeira de Linguística Descritiva das Línguas Bantu no curso de graduação em Letras da Universidade Eduardo Mondlane. A ideia de Gumperz de que "comunidades de fala, amplamente concebidas, podem ser consideradas como coletivos de redes sociais" (GUMPERZ, 1996, p. 362) sugere que elas não são um construto pré-existente, mas antes o resultado de um conjunto particular de práticas linguísticas. Por isso, recortei do universo mais amplo definido como comunidade de fala um subgrupo no qual pude observar a dinâmica das línguas em contato e os valores sociais atribuídos a elas e que tem sido definido por alguns sociolinguistas como comunidade de prática:

Comunidades de prática são definidas por três características especiais: engajamento mútuo, a negociação em conjunto de um empreendimento, e um repertório compartilhado. Um exemplo de uma comunidade de prática é uma banda de rock de escola. [...] Na verdade, muitos outros grupos de adolescentes podem legitimamente ser considerados comunidades de prática porque envolvem "um processo de aprendizagem social." [...] As comunidades de prática são essencialmente agentivas, quero dizer, constituem fóruns através dos quais os indivíduos exercitam volitivamenente aspectos de sua identidade. (TROUSDALE, 2010, p. 22)

Muitas vezes saíamos da aula, e eu seguia um dos estudantes ou um pequeno grupo para acompanhá-los em suas atividades diárias. Aos poucos comecei a ter acesso a âmbitos da vida moçambicana a que não teria caso não 
fosse acompanhada por eles nesse trabalho constante de observação participante. Além disso, o fato de os participantes serem familiarizados uns com os outros e terem uma interação localmente reconhecida, espontânea, não forçada, significou que, à medida que me fui incorporando ao grupo, eles passaram a manter o mesmo tipo de interação, ainda que na minha presença. Embora as especificidades deste local pudessem trazer diferenças quanto à cultura local, o fato de ter percebido nas primeiras semanas de aula que presenciaria um grupo de prática atuando não apenas em um português proficiente, como em outras tantas línguas foi fascinante, talvez a primeira experiência etnográfica reveladora: que aquele microcosmo me daria acesso ao macrocosmo da cultura linguística em Maputo. Como eram estudantes do curso de Letras em um país em que a questão linguística é conflitiva, todos deveriam ter opinióes sobre isso, convergentes, divergentes, reprodutoras de discursos oficiais ou contra eles. Ou seja, era um lugar de alta densidade de reflexóes metalinguísticas sobre o estatuto das línguas ao mesmo tempo que era um fecundo campo de práticas a serem observadas in loco. Eles tinham não apenas uma competência comunicativa plurilíngue, como também circulavam em âmbitos de vitalização e fortalecimento das línguas bantu, lugares em que eu poderia não apenas presenciar o contato entre as línguas como as tensóes decorrentes das diferenças de estatuto entre elas.

Os principais procedimentos da pesquisa dividiram-se em duas etapas. $\mathrm{Na}$ primeira, segui um diagnóstico sociolinguístico feito por um instrumento de pesquisa, aplicado a todo o grupo de estudantes da turma que eu frequentava e posteriormente sistematizado. Usei uma metodologia quantitativa metacognitiva, de acordo com Barcelos (2001), por meio da aplicação de um questionário com perguntas sobre o perfil sociolinguístico dos falantes, os domínios de uso das línguas e a maneira como concebem o estatuto das línguas faladas em Moçambique. Na segunda etapa, usei uma metodologia qualitativa do tipo contextual (BARCELOS, 2001), em busca de compreender as atitudes em contextos culturais específicos em uma pesquisa etnográfica durante seis meses. Acompanhei pela observação participante um pequeno grupo selecionado dentro do maior, com uma pluralidade de técnicas de pesquisa auxiliares, como gravaçóes, filmagens, registro em diário de campo, entrevistas com informantes-chave, narrativas autobiográficas, etc. Tomei como ponto de partida para a análise eventos de fala em diversas situaçóes sociais e analisei, além do contexto comunicacional, os participantes envolvidos, os papéis sociais que 
assumem, o tópico ou gama de tópicos que afetam a forma da mensagem verbal, os enquadres, as pistas conversacionais, buscando relacionar esses elementos ao estatuto das línguas em questão, seguindo a metodologia da Etnografia da Comunicação (HYMES, 1974; GOFFMAN, 1967 e 1979; GUMPERZ, 1974 , 1982a e 1982b). As vantagens de uma abordagem contextual são a observação de elementos situacionais como pausas, feições, trejeitos, respiração, alinhamento dos participantes na interação, etc. e o acompanhamento dos informantes da pesquisa como agentes sociais interagindo em seus contextos de atuação, relacionados à história de vida de cada um, bem como às suas redes sociais.

Considero que a abordagem metodológica ideal ao se tratar de atitudes deve combinar a pesquisa quantitativa (amostras grandes de informantes) que garantam a representatividade da comunidade de fala, com o detalhamento que a pesquisa qualitativa permite, a fim de que a segunda possa contextualizar e discutir aspectos encontrados nos dados levantados através da primeira.

Apresento, a seguir, as razóes pelas quais acredito que uma abordagem etnográfica - a exemplo do procedimento metodológico principal da Antropologia - pode ser muito útil para os estudos sociolinguísticos. Primeiro, porque ela descreve as práticas dos sujeitos, e não o que eles ou outros afirmam ou julgam sobre suas práticas. A etnografia tem a chance de trazer algumas fotografias dessas situaçóes. Isso significa, entre outras tantas vantagens, transformar informantes mudos em sujeitos com voz. Segundo, porque esse método é caracterizado pela incompletude, ou seja, o que se descreve é sempre provisório e contextualizado, sempre deixa aberta a possibilidade de novas perguntas e questionamentos permanentes sobre a questáo a ser reavaliada e ultrapassada (PEIRANO, 1995, p. 12). Uma terceira razão para defender esse método é o entendimento das práticas linguísticas do ponto de vista nativo, do saber local a respeito das línguas. Conforme Ortner:

É a nossa capacidade, sobretudo desenvolvida no trabalho de campo, de adotar a perspectiva do outro que nos permite aprender qualquer coisa - mesmo na nossa própria cultura para além do que nós já sabemos [...]. É essa nossa localização "no mesmo chão dos nativos" que nos permite ver as pessoas não simplesmente como reprodutores e reagentes passivos a um 
"sistema", mas como agentes ativos e sujeitos da sua própria história. (ORTNER, 2011 [1982], p. 439)

Um último motivo acresce utilidade aos métodos etnográficos: o fato de a questão estudada não ser ainda claramente compreendida, o que tornaria prematuro entrar na comunidade com um instrumento de pesquisa puramente quantificável. Registrei em quatro diários de campo com anotaçóes minuciosas e o mais objetivas possível (evitando interpretaçóes e inferências ad hoc) os seguintes itens: uma descrição dos cenários onde ocorriam as interaçóes verbais, quem eram os participantes envolvidos, a cronologia dos eventos (com datas e horas), descriçóes detalhadas dos comportamentos, registros de conversas e demais situaçóes de fala (aquelas que não pude gravar), com anotaçóes sobre os fatores paralinguísticos. Muitos epísódios de conversa entre mim e os sujeitos da pesquisa ou entre os sujeitos entre si, ou ainda entre eles e suas redes foram transcritos; apenas os que julguei mais relevantes para a análise transcrevi. Alguns desses fragmentos da interação são incorporados ao texto, com fonte diferente, de forma a transitar entre a descrição etnográfica e a reflexão teórica suscitada por ela. Um deles destaco a seguir, a fim de ilustrar a problematização de ordem teórico-metodológica que orientou o estudo: como medir atitudes linguísticas em uma situaçáo de plurilinguismo táo complexa, em que um falante de português com uma língua A como substrato interage com outros que têm as línguas $B$, C, D... como substratos, com possibilidades combinatórias e graus de proficiência variados?

“LEVAR PURRADA": o aprendizado de português na adolescência

28 de abril de 2012, aula de Linguística Descritiva das Línguas Bantu com uma turma de 60 estudantes, entre 18 e 30 anos, falantes das línguas: xichangana, xirhonga, cicopi, emakhuwa, cinyungwe, cinyanja, cisena, ciute, cindao, cibalke, ximanyika, kiswahili, shimakonde, emetto, cithswa, gitonga, português, inglês, francês, italiano, árabe. O professor entra em sala e repreende os alunos porque fizeram "péssimos trabalhos". Ele os aconselha a procurar material sobre as línguas bantu no Google. Alega que não sabem fazer um ensaio e que escrevem mal em português. Um dos rapazes queixa-se: 
Situação de fala: aula de Linguística Bantu

P: professor

A: aluno da etnia manyika

A1: Professor, a bibliografia do trabalho era toda em inglês, e nós não percebemos $^{6}$ bem o inglês...

P: Como me dizem que o inglês é um problema? Esta é uma cadeira de todas as línguas, vocês têm que saber, são as suas linguas. Se não sabem, digitem lá no Google o nome das suas linguas e pesquisem sobre elas. Vocês têm que saber uma coisa: hoje eu vou dar três fichas: uma sobre a morfologia em emakhuwa, outra sobre a morfologia do passado em cicopi, e outra sobre tempo e aspecto em xirhonga. Eu quero uma comparação dos três textos.

A2: E esses textos estão em inglês?

P: Sim. (A turma toda agita-se nas cadeiras, resmunga...)

Narciso: E não seria bom comparar com uma lingua da região central, como cimanyika, cisena, cishona?

P: Não é pela diferença administrativa que eu proponho... mas pela diferença morfológica entre as línguas... Vocês hão de ver que somos tão diferentes, que se cada um escrevesse um texto de quinze linhas na sua lingua e trocássemos, veriamos o quanto somos diferentes...

Nem sempre os alunos, que são proficientes no sistema oral das línguas, sabem escrevê-las no quadro negro ou falar sobre elas com a metalinguagem usada em um curso de Letras, ou seja, não dominam a padronização ortográfica, não dominam as categorias morfossintáticas para a explicação das línguas que usam. Algumas línguas são socialmente mais estigmatizadas que outras, e os seus falantes vão progressivamente mostrando timidez. Em outras palavras, se por um lado eles são proficientes nas línguas autóctones (alguns mais, outros menos), a aprendizagem de uma escrita e leitura acadêmica e metalinguística a respeito dessas línguas não é igualmente fácil, apesar de ser cobrada dos alunos neste momento na universidade. Isso gera um círculo vicioso em termos de estatuto das línguas. Há uma circularidade entre o não reconhecimento oficial e a não valorização sociossimbólica das línguas bantu nestes contextos mais escola-

6 O verbo "perceber" é usado no português moçambicano com um sentido levente diverso do usado em português brasileiro. "Perceber" significa "compreender", "entender" algo. 
rizados ou urbanos. Consequentemente, a institucionalização do português e os instrumentos linguísticos decorrentes dela (literatura, gramáticas e dicionários) aumentam o seu reconhecimento simbólico, e diminuem ao mesmo tempo o desenvolvimento funcional das línguas autóctones não oficializadas, já que elas não dispóem desses instrumentos que as tornariam socialmente promovidas.

Por exemplo, uma professora do departamento de Línguas Bantu afirma que, mesmo no curso de Xichangana, no primeiro dia de aula, nenhum aluno se declara falante da língua. Os alunos não se sentem autorizados a falar 'dialeto’ na universidade. Depois, começam a surgir exemplos de palavras pipocados aqui e ali e eles começam a assumir.

Vejo a cada aula rapazes de Maputo e também de outras regióes do país tentando dar exemplos e analisá-los. Às vezes as formas de falar uma mesma língua são muito diferentes. Três pessoas originárias de Quelimane, capital da Zambézia, apresentam três formas diferentes de escrever o mesmo verbo. Os meninos, na faixa etária entre 20 e 25 anos, têm muita vontade de aprender e prestam muita atenção à aula. Conseguem manter a atenção durante duas horas, em silêncio, em uma turma de mais de 60 pessoas seguindo um raciocínio de análise metalinguística que muitas vezes não compreendem. Nesta aula, uma menina franzina, com extensões (tranças afro) no cabelo diz: "Os estudantes não têm orgulho de dizer que são falantes de alguma língua bantu ou que são estudantes de línguas bantu”, ao que o professor responde com uma longa explanação sobre atitude: "O problema que se levanta sobre as línguas bantu é de atitude, não de ciência. Para estudar essas línguas, precisamos de bons linguistas. Eu, quando falo de atitude é isso: cada um de nós tem problema de apresentar sistematicamente a língua dele. Nós não conhecemos a nossa língua”.

Na saída da aula, perguntei à menina, que reconheço depois como sendo a Manuela, se podia entrevistá-la. Ela combinou de dar uma entrevista no dia seguinte. Disse que se interessava por saber mais sobre essas questóes que eu estudava, mas que não pensava em seguir carreira acadêmica, pois parece que isso é "muito distante de alcançar para nós".

No dia seguinte, ela começa por me sugerir assistir às cadeiras de Literatura Moçambicana dos professores Aurélio Cuna e Francisco Noa. Antes de eu começar a gravar, ela diz que são cadeiras que nos ajudam a compreender por que nós, moçambicanos, temos um caráter, uma identidade tão dividida. 
Situação de fala: Entrevista etnográfica

L: Letícia

M: Manuela

L: Explica-me melhor isso que falaste sobre ter uma identidade dividida.

M: Essa negação das linguas acontece entre as pessoas escolarizadas, no ambiente acadêmico. Se a gente sai daqui da cidade vai a um distrito, por exemplo, a Boane, quando chega lá toda gente fala uma lingua bantu. É por isso que agora estão então a tentar usar o ensino bilingue em Moçambique, mas sabemos que nas cidades isso não vai acontecer, aqui na cidade é impossivel. Na cidade de Maputo, sobretudo, os pais não suportam a ideia de saber que o seu filho vai à escola aprender uma lingua bantu.

L: Por quê?

M: Porque a nossa colonização aqui foi uma ocupação do espaço geográfico, mas também do espaço psicológico. Para uma pessoa ter o estatuto de cidadão naquela altura, tinha que abdicar de suas tradiçóes, e inclusive aprender a falar português. Só assim era considerada uma pessoa de verdade. Então esse esforço de abandonar suas linguas, sua cultura; nós somos frutos de uma geração que passou por esse processo. Isso fez com que as linguas bantu fossem abandonadas.

L: Mas hoje há uma tendência a voltar a se falar lingua bantu?

M: Se tu ouves alguém a falar linguas bantu naquele espaço as pessoas vão olhar-te como um individuo marginal, como individuo. Eu, particularmente tenho certas reservas de falar lingua bantu em certos lugares. Pra mim, não é fácil falar lingua bantu aqui na faculdade, porque eu era proibida na infância de falar lingua bantu, então, para mim que eu não conseguia assumir com naturalidade. Não é uma coisa que as pessoas falam, depende dos valores que nós temos.

L: Como foi tua escola básica? Foi aqui em Maputo?

M: Sim, foi aqui na Matola, em 1993. Nós aprendemos português na es-co-la. Eu lembro que eu não sabia falar português. Mas uma vez, na escola, era pro-i-bi-do falar a lingua bantu (ela se exalta e começa a falar mais alto). Isso era pra que? A gente tinha que inventar formas de comunicar-se em português. Nem sempre entendiamos o que a pessoa falava...

L: Como o professor garantia isso?

M: Porrada. (Ela pronuncia "purrada", carregando bastante nos "rrr") Umas palmadas na mão com uma régua de madeira. Eu lembro que... isso era coisa erra- 
da, era um erro muito grande falar língua bantu... a gente foi crescendo assim. Eu na oitava classe, estudava numa escola grande, com pessoas de lugares diferentes, $e$ elas falavam linguas bantu na sala de aula. Aquilo... Eu pensava como era possivel alguém falar bantu na sala de aula com tanta naturalidade... Olhávamos para eles com certo desprezo.

L: Mas falavam bem em português?

$M: N$-n-não (ri)... o nosso vocabulário era muito restrito.

L: E quando saía da escola?

M: Eu falava changana em casa, com a minha familia. Mas fora tinha vergonha de falar changana pensando que algum colega da escola podia estar ali.

L: Como assim? Ele podia contar aos outros?

M: Não, não... não era porque ele podia denunciar... era porque era vergonhoso. Eu tinha de fingir que eu falava português...

L: E os teus pais?

M: A única preocupação do meu pai era que nós soubéssemos falar português, porque sabia que iamos enfrentar dificuldades... Então, no dia em que ele nos matriculou na escola, ele disse: "Vocês não podem mais falar changana, vocês têm que passar a comunicar-se em português. Isso demorou um tempo para mudar. Hoje, em casa, eu só falo português. Meus irmãos mais novos têm como língua materna o português, porque já não falávamos mais changana em casa. Nós só falamos changana com minha avó.

L: Ontem, na aula, houve um momento em que o professor respondeu a uma pergunta tua. O que tu falaste? Eu estava ao fundo e não ouvi bem.

M: O professor estava a dizer que os estudantes de bantu saem-se melhor. Ele acha que moçambicano tem que ir a faculdade fazer ensino de linguas bantu, eu sinto isso nele, e eu disse "mas eles não conseguem assumir as suas linguas, não tem a-ti-tu-de de assumir a sua lingua bantu". Muitos entram para o curso de bantu como segunda candidatura. Entram para mudar depois. É um meio de ter acesso à universidade, mas para depois mudar e fazer outro curso. Matriculam-se, e depois quando tu perguntas: "que curso estás a fazer?" Eles não dizem.

L: Na tua opinião, isso tem a ver com não se poder falar desde a infância, na escola?

M: Sim, mas tem a ver também com o mercado. Se eu vou fazer bantu, que é que vai ser de mim, que tipo de trabalho eu vou ter? Na cabeça de algumas pessoas, isso é inconcebivel, uma coisa absurda. É assim, quem faz formação em 
linguas bantu é um sujeito que assume que ele é um bantu e que essa que é a realidade dele. Uma percentagem muito pequena assume isso. Para despertar nas pessoas esse amor, esse orgulho pela lingua, é preciso muito mais do que isso. O exemplo tem que vir de cima, dos nossos dirigentes, por isso é que eu acho absurdo alguém ir a aprender linguas bantu. Os documentos oficiais estão todos escritos em português.

L: Mas tu não deixaste de falar changana, quer dizer, ainda usas a lingua apesar disso tudo que dizes...

(Ela muda o tom de voz, visivelmente, fica mais titubeante nas respostas)

M: É... eu acho que isso é uma questão de identificação, no fundo acho que ainda prevalece uma certa identificação com as nossas linguas, acho que é isso.

L: Onde tu usas capulana?

M: Eu uso capulana nas cerimônias fúnebres, nas situaçóes indispensáveis, mas eu não venho pra cidade de capulana (risos), pra faculdade de capulana. Acho que a gente não assume por várias questóes, mas nós sabemos que is-so é nos-so. Sinto que nós temos que preservar de certa forma. Se eu vou à terra do meu pai, eu náo posso chegar lá e falar português, tenho que falar com todo mundo em changana.

L: O que acontece se falares em português?

M: Primeiro, eles não sabem, não sabem mesmo, não entendem.

L: Mas o teu pai poderia, por exemplo, fazer a tradução.

M: Se eu faço isso, as pessoas que estão ai à volta vão interpretar isso como um... um... como é que eu posso dizer, é... será como se eu estivesse a me distanciar daquelas pessoas, me colocar num nivel superior em relação a elas. É assim como vão encarar e não vão gostar.

L: O que perdes com isso?

M: Eu... Hum... o pertencimento ao grupo... a pertença perde-se. As pessoas como são muito humildes e conhecedoras de práticas de magia ... eh... (ri nervosamente) pode até ser que alguém odeie tanto isso a ponto de... como dizer... (fica muito embaraçada) pode até... fazer um feitiço.

L: Como se através da lingua...

M: [eu marcasse um distanciamento.... eu não pertenço mais, eu estou aqui... imaginas que tu, mesmo sem fazer parte do grupo, se vais lá, és obrigada a fazer certas coisas. Imaginas se és do grupo, só porque voltas da cidade te negas a falar, eles podem odiar isso ao ponto de... fazer alguma coisa. 
L: Todas as cerimônias, o lobolo, a invocação dos mortos, tudo é feitos nas nossas línguas porque... não se faz cerimônia tradicional em português?

M: Não, não tem efeito nenhum. Não tem nenhum sentido fazer isso em português. Ir à nossa terra, falar a nossa lingua é como se estivéssemos a falar com os nossos antepassados.

L: Mas aqui na universidade....

M: Hmhm... (faz sinal negativo com a cabeça)... a gente até pode negar isso entre colegas...no transporte público, no shopping... mas no fundo a gente sabe que alguém pode fazer um feitiço e pegar.

L: Se houvesse uma politica de línguas, como no Zimbábue ou na África do Sul, em que as linguas fossem oficializadas, tu achas que isso mudaria a tua atitude?

M: Claro. É o que estava a te dizer: é uma questão de querer atingir um certo estatuto ou um certo nivel acadêmico. Você tem que mostrar pros outros, falar na língua portuguesa ai fora... é uma opção. Você tem que mostrar pras pessoas que você tem um dominio da lingua portuguesa. Por outro lado, você tem que estar com a sua etnia e saber falar a sua lingua.

$L:$ E tu vais ensinar aos teus filhos alguma lingua bantu?

M: Não, eu penso que não. Eu vou falar com eles só em português...

Minha conversa com Manuela parte de sua própria ideia sobre ter uma "identidade dividida". Quando lhe peço que me explique, ela cita duas oposiçóes nos âmbitos de uso das línguas: a primeira diz respeito ao continuum rural-urbano e se dá entre o distrito, onde "toda gente fala uma língua bantu", e a cidade, onde ela considera "impossível" o ensino bilíngue, já que os pais "não suportam" que o filho vá à escola aprender uma língua bantu. A segunda oposição se dá no continuum da escolarização, em que ela demonstra, no transcorrer dessa pequena narrativa biográfica, um afastamento da língua bantu à proporção que ascende no ambiente acadêmico, onde ela se envergonha de falar como um "marginal”, porque é "inconcebível”, "uma coisa absurda”. É interessante perceber que ela própria atribui as raízes desse sentimento de rejeição ao contexto de colonização que ocupou um espaço "psicológico", além do espaço físico, e obrigou as pessoas a "abandonar suas línguas, sua cultura". A coibição e a proibição do uso das línguas na infância - inclusive com episódios de violência física - deixaram marcas, memórias, atitudes, reaçóes. Não obstante a sua per- 
cepção das causas desse processo, ela parece aquiescer e reproduzi-lo discursivamente justificando as razóes para a sua renúncia ao uso das línguas bantu nesses ambientes. Manuela tem uma lembrança corporificada que se atualiza e confirma na prática de por que não deve usar uma língua bantu na universidade, por exemplo. Afirma ter "certas reservas" e que "não é fácil”, mas reconhece que há diferenças nesse discernimento dependendo dos "valores de cada um". Ela própria conta do seu espanto ao ouvir outras crianças falando com naturalidade línguas bantu em sala de aula. Minha observação de seu comportamento, bem como o de seus colegas em aula e em outros ambientes, é de que as atitudes em direção às línguas variam muito de acordo com os efeitos retrospectivos desses fatores biográficos, com as diferentes formas de incorporação dos valores das línguas ao longo da vida.

No entanto, Manuela muda de posição, de enquadramento (footing), no mesmo cenário, com o mesmo interlocutor, quando o assunto deixa de ser o uso das línguas bantu no ambiente urbano e acadêmico e passa a abordar a relação entre línguas bantu e a família alargada. Mesmo quando o tópico envolve família, a atitude sobre a língua portuguesa é diferente se o grupo de referência é o pai, as tias ou os seus próprios filhos. Assim, atualiza-se no mesmo falante, em um único evento de fala, uma série de tensões entre o significado social das línguas. A língua portuguesa e o xichangana assumem estatutos diversos conforme o grupo de referência que ela tem em mente (os seus colegas, as pessoas escolarizadas, o pai, os irmãos, a avó, a professora primária, as tias na aldeia, os professores universitários, os seus futuros filhos), ou a memória e as representaçóes dos tempos e espaços (o passado colonial, a escola, a casa, a vizinhança, o shopping, a universidade, etc.). A oposição social elementar não se encontra "lá fora" na sociedade, ou na comunidade de fala heterogênea, mas antes no seio de cada indivíduo social, cada vez que ele vacila entre adotar ou rejeitar um novo modelo, padrão, atitude em relação à lingua. Manuela usa os termos distanciamento e pertencimento para definir duas dentre muitas atitudes possíveis. Em cada dúvida, em cada ato de fala em que ela se "contradiz", em cada prática e seus múltiplos desdobramentos, há, de um lado a atualização das relações coloniais, mas há também, de outro, ansiedades, adaptaçóes e lutas contemporâneas para lidar com esse passado e reconfigurá-lo, enriquecendo os repertórios e as estratégias locais para lidar com ele. As dinâmicas específicas com que cada ator social responde a essa 
tensão de resistir ou conceder, de adotar, repetir ou se opor é que produzem esse cosmopolitismo linguístico, que, na soma das escolhas de todos, vai reproduzindo-se e/ou transformando-se.

Como se verifica nessa entrevista de Manuela, o conceito de atitude linguística pode ser um tanto evasivo. Isso diz respeito tanto à dificuldade metodológica de levantar e medir aspectos comportamentais sobre variantes ou variedades linguísticas mutáveis entre as pessoas, mas também em uma pessoa só. Outra dificuldade é correlacionar atitudes com comportamentos específicos, como se estes fossem decorrentes daquelas. Ao longo da entrevista, percebe-se tanto uma coerência entre o que Manuela afirma expressamente e o que ela faz de fato (em certos domínios, como a faculdade de Letras) quanto uma brecha entre essa crença e o seu comportamento (em outros domínios, como a casa das tias em Boane). Esses sentidos para as línguas, aparentemente disjuntivos, levam-nos a crer que o funcionamento sociopsicológico dos indivíduos de comunidades linguísticas plurilíngues em que o estatuto das línguas é muito variável não é igualmente válido para todos os subgrupos que dela fazem parte. Tudo isso nos leva à pergunta: o que acontece com o uso de uma língua quando a correlação entre atitude, motivação e comportamento varia contextualmente, muitas vezes parecendo inconsistentes e contraditórias entre si? Como o falante gerencia essas aparentes contradiçóes?

\section{A alternância de atitudes sobre o significado social das línguas em contato}

O fato de muitos moçambicanos terem uma língua bantu como língua materna, e estarem em permanente contato com línguas de estruturas diversas, entre elas o português, facilita o surgimento de certos fenômenos do plurilinguismo em que o valor social das variáveis ganha maior diversidade e flexibilidade. A alternância e mistura de códigos (code-switching ou code-mixing), os empréstimos, as interferências são apenas alguns entre eles. No entanto, não é fácil relacionar a complexa estrutura do repertório linguístico com os significados sociais do comportamento verbal dos falantes, em razão da amplitude dos fatores envolvidos, incognoscíveis em seu conjunto. Por exemplo, o sentimento de identificação com as línguas locais ou a preferência pelo português não variam apenas entre os falantes conforme a etnia, escolaridade, sexo, idade, bairro, 
mas em um mesmo falante conforme a situação de fala, o tópico, os interlocutores, a intenção, etc. Quanto maior a gama de relaçóes pessoais do indivíduo, quanto mais alargada é sua rede social, maior variabilidade terão os estatutos das línguas, e a alternância de atitudes sobre elas tende a ser frequente e instável conforme, inclusive, os repertórios linguísticos dos outros falantes com que entra em contato ao longo da vida.

Assim, confirmando um pressuposto da Sociolinguística Interacional, o valor social de uma língua não é um dado adquirido: ele é contextualizado e renegociado a cada ato de fala (GUMPERZ, 1982a). O que o contexto estudado em Maputo mostra é que, em uma situação plurilíngue, se multiplicam de tal forma as possibilidades de alternância desses valores na negociação, que o que chama a atenção não são as atitudes em si, mas a transferência de uma atitude a outra, ou seja, a relação no mesmo falante entre uma atitude favorável e desfavorável em relação à mesma língua em um espaço muito curto de tempo (ou ainda uma atitude favorável em relação a duas ou mais línguas com estatutos sociais muito diferentes). A questão é: o que acontece quando a competência comunicativa envolve muitos desempenhos com muitas estruturas profundas que na interação assumem significados sociossimbólicos diversos? A "competência comunicativa plurilíngue" consistiria na soma das escolhas entre as possibilidades e restriçóes em cada língua separada? Ou a percepção que o falante possui do significado social das línguas em seu conjunto pressupõe o estatuto de cada escolha? Como se dá essa dialética na prática? Há uma hierarquia, uma espécie de diglossia encaixada situacional e idioletal?

Os métodos de pesquisa atitudinal da Psicologia Social e da Sociolinguística Variacionista, por exemplo, buscam em seus modelos teórico-metodológicos correlacionar esses valores sociais a fatores linguísticos e extralinguísticos e quantificá-los, dando muitas vezes um panorama abrangente das tendências das atitudes de tal sociedade sobre as línguas envolvidas no contato. $\mathrm{Na}$ crítica teórica que gostaria de construir em relaçáo a esses métodos - tendo como pano de fundo o cenário plurilíngue de Moçambique -, defendo que a esses panoramas "macro" escapam detalhes e sutilezas que uma descrição etnográfica das práticas linguísticas, contempladas do ponto de vista do saber local sobre as línguas, permite. $\mathrm{O}$ método mais aproximado para este tipo de trabalho é o da Sociolinguística Interacional, que busca focar sua análise na interpretação dos valores sociais nos usos das línguas em interação. O processo, como 
indicam Gumperz e Blom (1972), consiste de duas etapas: na primeira, os falantes captam pistas externas do ambiente e traduzem-nas em estratégias de comportamento adequadas; na segunda, essas estratégias de comportamento são por sua vez traduzidas em símbolos verbais. "Os determinantes deste processo comunicativo são os conhecimentos que o falante possui do repertório linguístico, da cultura e da estrutura social, e sua capacidade de relacionar esses conhecimentos às restrições ou balizas contextuais" (GUMPERZ; BLOM, 1972, p. 65). Dessa forma, para os autores, o valor das línguas é definido situacionalmente, seguindo, principalmente, dois fatores que devem ser analisados: o contexto (cenário) e os papéis sociais que os falantes assumem nele. As características socialmente significativas de cada ambiente de interação imporiam restrições de motivaçóes e de ação. Isso já foi exaustivamente tratado na literatura sociolinguística e ganhou nomes diferentes, como situação de fala (Goffman, 1964, Hymes, 1964), cenário (Blom; Gumperz, 1972), domínios de uso (Fishman, 1972), fatores condicionantes (Labov, 1972).

No entanto - e aqui desponta a questâo crucial, para mim, a que tais modelos não respondem -, esses âmbitos geralmente não são considerados em sua mobilidade e flexibilidade, e sim dados a priori: são considerados como anteriores, ou explicativamente superiores e vitalmente posteriores (duram mais que) os atos de fala. Parte do problema levantado por mim neste estudo diz respeito ao fato de a literatura sciolinguística considerar que atos de fala e contexto são essencialmente separados, aqueles sendo condicionados por este. E se concebêssemos que ambos são inseparáveis? Ou se pensássemos que os atos de fala é que produzem o contexto? Que o contexto nada mais é do que a articulação desses atos de fala, de diversos e muitos atos de agentes envolvendo escalas de valores e poderes diversos? Portanto, prefiro a ideia de âmbitos de eficácia das línguas porque privilegia não apenas os territórios, os espaços onde as falas acontecem, ou os fatores condicionantes dos usos, mas a relação, o resultado da ação, as práticas, as potências envolvidas na cena em si. Por exemplo, se é um ritual cerimonial, se é uma sala de aula, se é uma brincadeira na rua ou uma conversa na mesa do bar, as potências das línguas envolvidas, a sua eficácia, os seus valores sociossimbólicos e os ganhos que os falantes têm em cada situação não podem ser generalizados nem pressupostos.

Isso não tira a importância dos fatores contextuais. A ferida colonial não está cicatrizada. O pertencimento étnico tem inegável relevância. O português 
é de fato a língua de mais prestígio em ambientes institucionais. E a etnografia mostra que Manuela e os seus outros colegas alternam suas atitudes perante as línguas conforme as situaçóes de uso e os interlocutores. Especialmente diante dos mais velhos, nos rituais que envolvem antepassados, ou nas aldeias, no ambiente rural, local onde a penetração do português é quase nula, optam pelo uso das línguas bantu e têm em relação a elas uma atitude favorável. Quando mudam de cenário, no pátio da sua casa, diante dos colegas, nos mercados, assumem-se falantes de línguas várias, conforme a situação. Porém, o cenário muda porque mudam os poderes vários que determinam o estatuto e o valor das línguas em contato; o seu conjunto em cada situação cria esses cenários, ou seja, os âmbitos de eficácia das línguas. Assim, o cenário e o evento são o pano de fundo para a eficácia, o poder de intervenção, de ação dos sujeitos. Quanto mais a situação reproduz as persistentes diferenças culturais de processos subalternos efetuados pelo encontro colonial, como uma aula na universidade, uma consulta médica no hospital, um congresso de "lusofonia", ou uma audiência pública - tanto mais atento é o uso das línguas e expressóes com que os falantes respondem a essa diferença colonial ${ }^{7}$.

Reitero que a ideia de dominio ou cenário permite imaginar uma série de acontecimentos sociais distintos, envolvendo performatividades várias, mas centra-se na fotografia da situação, ao passo que a ideia de âmbito de eficácia está relacionada à agência, à mudança de atitude, ao fluxo, ao travelling. Em outras palavras, um mesmo cenário, dependendo das restriçóes à interação proporcionadas pela mudança de participantes e de objeto da interação, pode dar lugar a muitos eventos de fala diferentes, e cada um pode envolver atitudes diferentes também. Por exemplo, o que significa o fato de, no microcosmo de uma aula de Linguística Descritiva das Línguas Bantu proferida em português, algumas línguas reproduzirem os mesmos lugares de poder e de marginalidade perpetrados durante a colonização? E o fato de os estudantes mudarem de registro, de prática e de atitude quando chegam ao pátio da Universidade, ou em casa?

Fui surpreendida no trabalho de campo por um tipo de alternância que não é incomum em Maputo: a alternância de atitude sobre as linguas na mesma situação de fala. Na entrevista que me deu na Universidade, por

7 Tomada aqui como dimensão ontológica da persistência do colonialismo, da colonialidade do ser, da subalternização e do epistemicídio de outros conhecimentos e práticas devido ao encontro colonial (SOUZA SANTOS, 2006) 
exemplo, Manuela muda de atitude três vezes em relação ao português e ao Xichangana, conforme o tópico ou o assunto: (a) o ensino bilíngue e o uso das línguas no meio urbano, (b) depois o uso do Xichangana entre as tias no ambiente rural, e (c) finalmente a transmissão geracional - ensinar as línguas aos filhos (ou seja, com o mesmo interlocutor, na mesma situação de fala (entrevista), o que a fez mudar de atitude foram tensões que existem sobre as línguas dentro dela mesma). Muitas vezes, a tensão social básica, mínima, não é entre duas pessoas, duas classes sociais, ou duas línguas... mas entre ideias e heranças no mesmo sujeito; entre as representações que eles têm daquelas pessoas, línguas, lugares, assuntos, situaçóes, etc. Mostra-se, em cada dúvida, em cada contradição, em cada escolha e suas múltiplas relações, a atualização de relaçóes coloniais, nas quais os atores sociais estão em permanente avaliação social. Nenhuma declaração, portanto, é vista como definitiva, nenhuma sentença é vista como final. Assim, o terreno dos poderes está em constante transformação, a partir das tensôes, hostilidades, resistências e concessooes perpetradas pelos agentes dessas mudanças, responsáveis não apenas por reproduzir, mas por alterar e construir essas relações herdadas da diferença colonial.

\section{Considerações finais}

Embora fortemente balizada por normas sociais, a alternância atitudinal (mudar o axioleto dentro do mesmo repertório linguístico, ou seja, a alternância entre a variedade linguística que tem mais valor sobre as outras) demonstra que há uma relação dialética entre os fatores determinantes pela estrutura social e a liberdade de escolha das línguas nos eventos de fala pelos participantes na conversa. Ou seja, a determinação de axioleto náo pode ser considerada apenas estrutural e social, mas também contingente e individual. É na soma das decisóes baseadas nos repertórios linguísticos em contato que se dáo essas relaçóes, e elas estão circunscritas nos processos sócio-históricos. Podemos situar, entấo, cada fala em círculos concêntricos de estágios consecutivamente mais complexos no processamento que o falante diz da informação contextual: atos de fala>eventos de fala> situaçóes de fala>cenários. Se cada estágio inclui aquele que o antecede, de forma que o precedente é parte do insumo que afeta a seleção de regras do seguinte, a decisão do falante não se dá sem 
uma atenta e imediata identificação quanto à natureza do evento em questão; consequentemente, a sua atitude segue essa variabilidade. Assim, o âmbito de atuação perpassa todos esses níveis e diz respeito à atitude que motiva a ação do falante (práxis).

Assim, arrisco a afirmar que não se pode falar em "a língua portuguesa", ou "o português moçambicano". Quando Manuela fala que só vai ensinar português para os seus filhos, ela está referindo-se a uma certa língua. Quando ela diz que não pode aceitar que o curandeiro fale em português ou que a tia não admite que ela fale em português lá na aldeia em Gaza, está se referindo a outra língua. "Português" para ela, nessas duas acepçôes, assume um valor sociossimbólico quase oposto. $\mathrm{O}$ enorme deslocamento que ela faz deve-se a essa zona de fronteira que permite tal hibridismo identitário. Não se trata de uma contradição, pois a definição de língua passa pelo estatuto, pelo significado sociossimbólico que assume para o falante em situaçóes de fala específicas. Assim, conforme Firmino (2014), em tal situação de plurilinguismo, nem se pode falar de línguas, mas de categorias linguísticas. Os limites entre uma e outra são tão difusos e imprecisos quanto os significados sociossimbólicos que podem adquirir em cada evento de fala.

\section{Referências}

ALTENHOFEN, Cléo V. \& BROCH, Ingrid K. "Fundamentos para uma 'pedagogia do plurilinguismo' baseada no modelo de conscientização linguística (language awareness)". In: BEHARES, Luis (org.). Atas do V Encuentro Internacional de Investigadores de Politicas Linguisticas. Montevideo: Universidad de la República e Associación de Universidades Grupo Montevideo / Núcleo Educación para la Integración, 2011. p. 15-22.

ANGROSINO, Michael. Etnografia e Observação Participante. Porto Alegre: ARTMED, 2008.

BARCELOS, A. M. B. "Metodologia de pesquisa das crenças sobre aprendizagem de línguas: estado da arte”. In: Revista Brasileira de Linguistica Aplicada. v. 1 n. 1: 71-92. 2001.

BLOM, Jan-Petter; GUMPERZ, John. "O significado social na estrutura linguística: alternância de códigos na Noruega”. In: RIBEIRO, Bianca Telles; GARCEZ, Pedro M. Sociolinguística Interacional. $2^{\text {a }}$ edição revista e ampl. São Paulo: Loyola, 2002. 
BRIGGS, Charles L. Learn how to ask: a sociolinguist appraisal of the role of the interview in social science research (studies in the social and cultural foundations of languages). Cambridge: Cambridge University Press, 1986.

CHIMBUTANE, Feliciano. Rethinking Bilingual Education in Post-Colonial Contexts. Clevedon/Avon: Multilingual Matters, 2011.

ECKERT, Penelope. Linguistic variation as social practice. Oxford: Blackwell, 2000.

FIRMINO, Gregório. A questão linguística na África pós-colonial: o caso do português e das línguas autóctones em Moçambique. Maputo: Promedia, 2002.

GEERTZ, Clifford. "O senso comum como sistema cultural”. In: O saber local. Petrópolis, RJ: Vozes, 1997.

. Nova Luz sobre a Antropologia. Rio de Janeiro: Jorge Zahar, 2001.

GOFFMAN, Erving. Interactional Ritual: essays on face-to-face behavior. New York: Anchor Books, 1967.

. Footing. Semiotica, v. 25, n.1/2: 1-29, 1979.

GONÇALVES, Perpétua. A génese do português de Moçambique. Lisboa: Imprensa Nacional/C da Moeda. 2010.

GUMPERZ, John. "Language in Social Interaction". In: Proceedings of the 8th International Congress of Anthropological and Ethnological Sciences, Tokyo: Science Council of Japan, 1968, p. 408-411.

. Discourse Strategies. Cambridge: Cambridge University Press, 1982a.

. Language and Social Identity. Cambridge: Cambridge University Press, $1982 \mathrm{~b}$.

HYMES, Dell. Foundations in Sociolinguistics: an etnography aproach. Philadelphia: University of Pennsylvania Press, 1974.

LABOV, William. Sociolinguistic Patterns. Pennsylvania: University of Pennsylvania Press, 1972.

MARIANI, Bethania. Colonização linguística. Campinas: Pontes, 2004.

. "Língua, colonização e revolução: discurso político sobre as línguas em Moçambique”, 2011, no prelo. 
NGOMANE, Nataniel. Lusofonia: quem quer ser apagado? Semanário SOL, 06/01/2012.

NGUNGA, Armindo. "O estatuto das línguas nas instituiçóes de ensino em Moçambique". Comunicação apresentada no Seminário da UNESCO sobre a disseminaçâo das linguas locais. Lusaka, Zâmbia, 1985.

. "O papel das línguas moçambicanas no desenvolvimento socioeconômico do país". Trabalho apresentado no I Seminário Nacional de Balanço do Ensino Bilingue em Moçambique. Maputo, 2008.

ORTNER, Sherry. Making Gender: The Politics and Erotics of Culture. Beacon Press, 1996.

. Anthropology and Social Theory: Culture, Power, and the Acting Subject. Duke University Press, 2006.

. “Teoria na antropologia desde os anos 60.” Maná 17 (2), 2011 [1984].

PATEL, Samima Amade. Olhares sobre a educação bilíngue e seus professores em uma região de Moçambique. Dissertação de Mestrado. Campinas, SP: 2006a.

- Um olhar para a formação de professores de educação bilingue em Moçambique: foco na construção de posicionamentos a partir do lócus de enunciação e actuação. Tese de doutorado. Orientador: Marilda do Couto Cavalcanti. Instituto de Estudos da Linguagem. Campinas, SP, 2012.

PATEL, Samima et al. Relatório do debate sobre Estratégias para o alargamento da Educação Bilingue. Maputo: INDE, 1997.

PEIRANO, Mariza. A favor da Etnografia. Rio de Janeiro: Relume-Dumará, 1995. 


\title{
PORTUGUESE AND LANGUAGES BANTU CONTACT IN MOZAMBIQUE: THE ATTITUDES SHIFTING TOWARD THE STATUS OF LANGUAGES AMONG UNIVERSITY STUDENTS
}

\begin{abstract}
This paper investigates the linguistic attitudes in a community of undergraduate Language students at the University Eduardo Mondlane in the city of Maputo (Mozambique), focusing on the status of Mozambican indigenous languages against the former colonial Portuguese.
\end{abstract}

KEYWORDS: Language Attitudes; languages of Mozambique; Ethnography of Speech.

Recebido em: 05/12/2016 Aprovado em: 09/12/2016 